\title{
"FESTA NA ESCOLA" - JOGO EDUCACIONAL DIGITAL PARA O ENSINO DE NÚMEROS E QUANTIDADES NA EDUCAÇÃO INFANTIL
}

\author{
Viviane Arruda Machado Leal ${ }^{1}$; Ana Marli Bulegon²
}

\section{RESUMO}

Este trabalho tem por objetivo apresentar o protótipo de um jogo educacional digital para ser utilizado no processo de ensino dos conceitos de Números e Quantidades na Educação Infantil, com crianças pré-escolares de 5 anos. $O$ jogo é um Produto Educacional desenvolvido no âmbito do curso de Mestrado Profissional em Ensino de Ciências e Matemática (PPGECIMAT), em parceria com estudantes bolsistas do curso de Jogos Digitais, da Universidade Franciscana (UFN). O tema do jogo "Festa na Escola" é o resultado da investigação realizada com professores da Educação Infantil sobre temas e preferências de brincadeiras e jogos lúdicos dos estudantes nesse nível de ensino. Desse modo as atividades do jogo compreendem: Jogo das Argolas, Boca do Palhaço, e Pescaria, constituídas de regras, pontuações e recompensas. Os conceitos de Matemática sobre números e quantidades presentes no jogo correspondem aos propostos na Base Nacional Curricular Comum (BNCC) para esse nível de ensino. O jogo terá acesso gratuito e poderá ser utilizado em computadores e tecnologias móveis.

Palavras-chave: Aprendizagem significativa; Estudantes pré-escolares; Ensino híbrido; Ensino de matemática.

Eixo Temático: Educação

\section{INTRODUÇÃO}

Um jogo educacional digital, quando planejado e proposto de forma coerente e clara no planejamento do professor, é um aliado na aprendizagem do aluno. A compreensão do jogo como um recurso lúdico pode tornar o processo de ensino e de aprendizagem mais significativos, oportunizando aos educadores utilizá-lo para incentivar o estudante a aprender através de jogos.

\footnotetext{
${ }^{1}$ Pedagoga, Mestranda do Programa de Pós-Graduação em Ensino de Ciências e Matemática (PPGECIMAT) - Mestrado Profissional - Universidade Franciscana (UFN), vivianeleal539@gmail.com 2 Doutora, Professora do Programa de Pós Graduação em Ensino de Ciências e Matemática (PPGECIMAT) - Universidade Franciscana (UFN), anabulegon@ufn.edu.br
} 
EDUCAÇÃO, SAÚDE

ETECNOLLOIA

26A 2EDE OUTUERO DE2021

As crianças desde pequenas têm contato com a tecnologia e o brincar faz parte do imaginário infantil. $\mathrm{O}$ uso da tecnologia no ensino aproxima os estudantes da realidade que estão inseridos.

Assim, a clareza na organização e utilização do jogo pensado e proposto pedagogicamente leva a oportunidade da aprendizagem ocorrer de forma prazerosa.

Como facilitador do aprendizado, os jogos digitais têm a capacidade de facilitar o aprendizado de várias áreas do conhecimento. Ao serem utilizados como um recurso de representação de um determinado assunto, os jogos auxiliam no processo de entendimento do que está sendo ensinado, por isso a importância dos professores utilizarem jogos na sua prática pedagógica porque os jogos além de facilitarem a aquisição de conteúdos, contribuem também para o desenvolvimento de uma grande variedade de estratégias que são importantes para a aprendizagem. (SAVI e ULBRICHT, 2008,p.3)

O jogo educacional digital alinhado com o planejamento do educador torna o ensino atrativo, lúdico e significativo. $O$ jogo estimula o estudante a explorar e criar estratégias de resoluções aos desafios propostos auxiliando o aluno a aprender através de questionamentos e descobertas.

É com esse pensamento que esse trabalho tem por objetivo apresentar o protótipo de um jogo educacional digital para ser utilizado no processo de ensino dos conceitos de Números e Quantidades na Educação Infantil. Esse jogo é o Produto Educacional desenvolvido no âmbito do curso de Mestrado Profissional em Ensino de Ciências e Matemática (PPGECIMAT), em parceria com estudantes bolsistas do curso de Jogos Digitais, da Universidade Franciscana (UFN).

\section{MARCO TEÓRICO}

O uso de recursos tecnológicos está presente no cotidiano da maioria das crianças, e a escola que os utiliza de forma planejada expande as possibilidades de aprendizagem. Crianças pequenas requerem propostas de ensino digitais que estejam de acordo com seus interesses, que ocorram de forma lúdica, espontânea, porém objetivadas pelo educador. Aprende-se e ensina-se por meio de experiências

\footnotetext{
${ }^{1}$ Pedagoga, Mestranda do Programa de Pós-Graduação em Ensino de Ciências e Matemática (PPGECIMAT) - Mestrado Profissional - Universidade Franciscana (UFN), vivianeleal539@gmail.com 2 Doutora, Professora do Programa de Pós Graduação em Ensino de Ciências e Matemática (PPGECIMAT) - Universidade Franciscana (UFN), anabulegon@ufn.edu.br
} 
EDUCAÇÃO, SAÚDE

ETECNOLOGIA

26A 2SOE OUTUERO DE2021

\section{QUFN}

e nas relações que se estabelecem na escola. E isso se dá de forma planejada e não é algo que acontece de qualquer jeito (SALLES; FARIA, 2012).

Nessa perspectiva, o professor é um mediador no ensino que precisa aliar a curiosidade infantil à intencionalidade no ensino. As atividades são planejadas respeitando os conhecimentos prévios dos estudantes, sendo organizadas para ampliá-los e reestruturá-los.

Nesse momento de enfrentamento ao Covid 19, com o ensino de modo remoto ou híbrido, a proposta de um jogo educacional digital pretende auxiliar a aprendizagem dos estudantes para que ocorra de forma prazerosa e significativa. No jogo, as regras são determinantes e devem ser respeitadas. Os jogadores precisam de consentimento mútuo dos participantes, aceitando e seguindo as regras acertadas previamente. Nesse sentido, a utilização de um jogo no processo de ensino auxilia o estudante a desenvolver a autonomia, o protagonismo e a criação de estratégias para a resolução de problemas.

O caráter lúdico, que os jogos apresentam, traz o esse como alternativa educacional. Porém, para que sejam utilizados com fins educacionais e eficazes no processo de ensino e aprendizagem, devem ser organizados e aplicados em consonância com o planejamento do professor.

[...] os jogos precisam ter objetivos de aprendizagem bem definidos e ensinar conteúdos das disciplinas aos usuários, ou então, promover o desenvolvimento de estratégias ou habilidades importantes para ampliar a capacidade cognitiva e intelectual dos estudantes (GROS, 2003, p.16).

As crianças pequenas precisam se sentir parte do processo para se dedicar e se concentrar em aulas remotas ou híbridas. O jogo digital permite o despertar da curiosidade da criança e sua utilização contribui para o desenvolvimento da autonomia em seus usuários e estimula a criação de estratégias para resolução de problemas. De acordo com Brougère (1998), o jogo só tem valor educativo se valorizado pelo professor. Dessa forma, o que caracteriza o jogo educacional é a atitude que envolve sua utilização e não o jogo em si.

\footnotetext{
${ }^{1}$ Pedagoga, Mestranda do Programa de Pós-Graduação em Ensino de Ciências e Matemática (PPGECIMAT) - Mestrado Profissional - Universidade Franciscana (UFN), vivianeleal539@gmail.com 2 Doutora, Professora do Programa de Pós Graduação em Ensino de Ciências e Matemática (PPGECIMAT) - Universidade Franciscana (UFN), anabulegon@ufn.edu.br
} 
EDUCAÇÃO, SAÚDE

ETECNOLOCIA

26A 2EDE OUTUERO DE2021

Nesse sentido, o educador precisa selecionar e organizar atividades digitais que promovam a ludicidade e o desejo infantil de participar. A fim de que o jogo educacional englobe conceitos básicos do conteúdo, a atividade didática que faz uso de um jogo deve iniciar com um questionamento sobre o conteúdo que será trabalhado, esse vem como um elo entre a aprendizagem e ludicidade.

No ensino de conceitos matemáticos jogos digitais facilitam a aprendizagem, pois fazem parte do cotidiano infantil. A utilização de jogos digitais aliados à educação agrega o aprender numa perspectiva dinâmica e benquista pela criança.

O jogo, na educação matemática, passa a ter o caráter de material de ensino quando considerando promotor de aprendizagem. A criança coloca diante de situações lúdicas, aprende a estrutura lógica da brincadeira, deste modo, aprende também a estrutura lógica matemática presente. Dessa forma, os jogos devem ser um grande caráter desafiador, sempre acompanhado de planejamentos, objetivos e metas. Devem ser escolhidos e preparados pelo docente com muito cuidado para levar o estudante a adquirir conceitos matemáticos de importância, que estimulem a resolução de problemas. (MOURA,2018 p.30)

Quanto ao jogo, seu planejamento precisa ter intencionalidade e regras claras e pré-definidas, a criança deve seguir as regras e respeitar a vez de jogar, entender o processo de ganhar ou perder inerentes ao jogo. Huizinga (2001) define o jogo como:

[...] uma atividade ou ocupação voluntária, exercida dentro de certos e determinados limites de tempo e de espaço, segundo regras livremente consentidas, mas absolutamente obrigatórias, dotado de um fim em si mesmo, acompanhado de um sentimento de tensão e de alegria... (p. 33).

O jogo educacional digital passou a ter destaque no ensino remoto ou híbrido pelo caráter lúdico e pela possibilidade de ser utilizado como recurso didático em atividades a distância. Sua aplicação, para ser significativa precisa ser organizada visando a motivação e intencionalidade no ensino de determinado conceito, unindo ludicidade à aprendizagem.

O jogo educacional é um meio de ampliar os conhecimentos prévios dos estudantes, pois respeita o que o aluno sabia sobre o tema e durante o jogo, pelas descobertas, a criança redefine sua teoria sobre o conteúdo.

\footnotetext{
${ }^{1}$ Pedagoga, Mestranda do Programa de Pós-Graduação em Ensino de Ciências e Matemática (PPGECIMAT) - Mestrado Profissional - Universidade Franciscana (UFN), vivianeleal539@gmail.com 2 Doutora, Professora do Programa de Pós Graduação em Ensino de Ciências e Matemática (PPGECIMAT) - Universidade Franciscana (UFN), anabulegon@ufn.edu.br
} 
Para tal, é necessário que o aluno esteja presente e atuando em favor de sua aprendizagem, bem como no fato do professor permitir, incentivar e promover situações para que o aluno atue, através de jogos ou resolução de problemas utilizando-se de ferramentas que ele já dispõe anteriormente (POMMER, 2013, p. 6).

A aprendizagem significativa, na pandemia, tem o jogo educacional digital como aliado tecnológico em tempos de isolamento social. $O$ jogo se torna ferramenta crucial na busca de ludicidade no planejamento digital, incentivando a motivação para aprendizagens concretas que tenham significado para os educandos.

\section{JOGO EDUCACIONAL DIGITAL "FESTA NA ESCOLA"}

O jogo educacional digital proposto terá uma sequência de fases com atividades que envolvam números e quantidades. A temática foi escolhida a partir de uma investigação prévia feita com professores da Educação Infantil sobre temas que despertam interesse nos estudantes, desse nível escolar. Aborda brincadeiras que ocorrem nas tradicionais festas escolares, suspensas na pandemia, como: Jogo das Argolas, Boca do Palhaço, e Pescaria (Quadro 1).

\section{Quadro 01- Descrição do Jogo "Festa na Escola"}

\footnotetext{
${ }^{1}$ Pedagoga, Mestranda do Programa de Pós-Graduação em Ensino de Ciências e Matemática (PPGECIMAT) - Mestrado Profissional - Universidade Franciscana (UFN), vivianeleal539@gmail.com 2 Doutora, Professora do Programa de Pós Graduação em Ensino de Ciências e Matemática (PPGECIMAT) - Universidade Franciscana (UFN), anabulegon@ufn.edu.br
} 


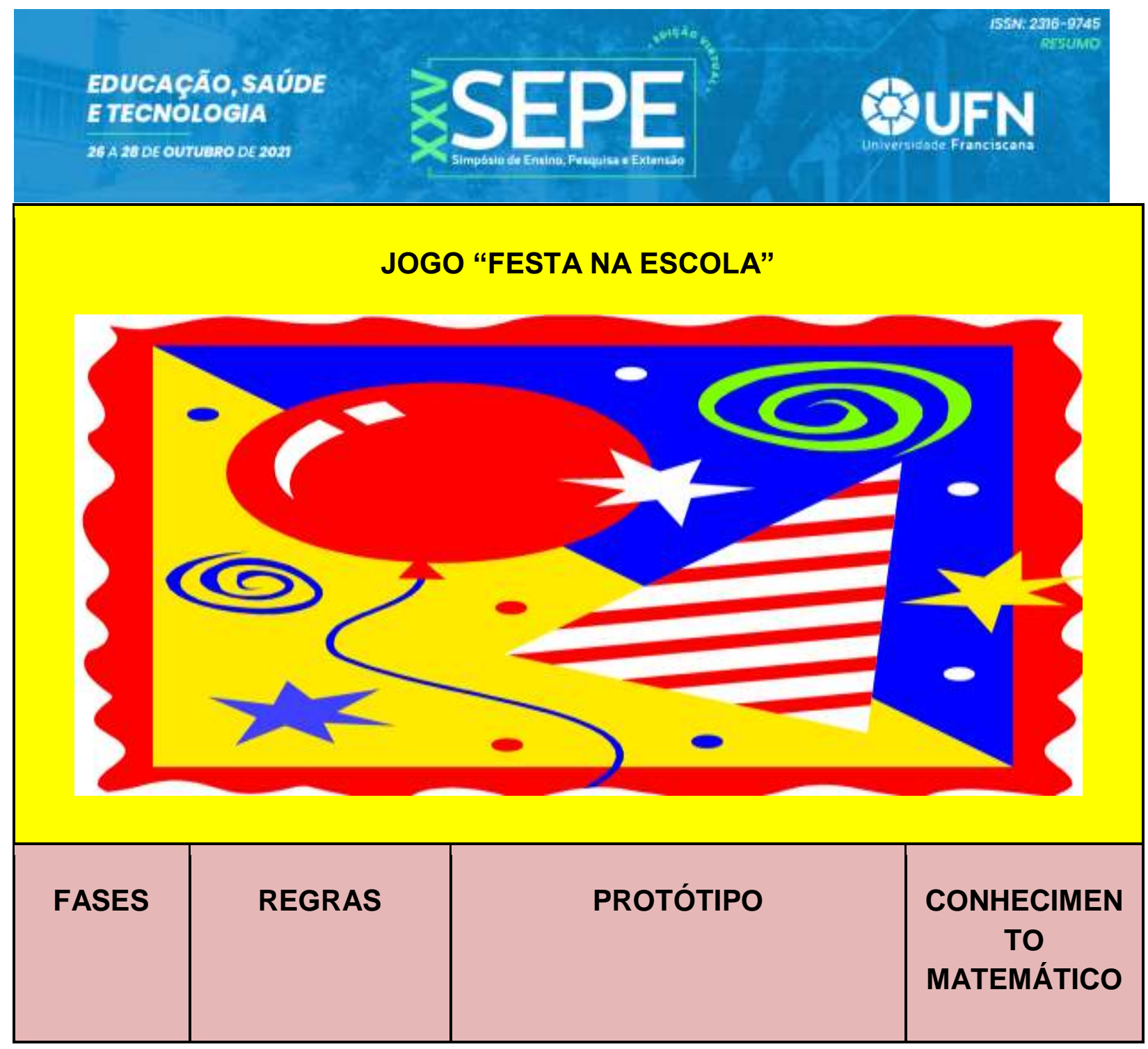

\footnotetext{
${ }^{1}$ Pedagoga, Mestranda do Programa de Pós-Graduação em Ensino de Ciências e Matemática (PPGECIMAT) - Mestrado Profissional - Universidade Franciscana (UFN), vivianeleal539@gmail.com 2 Doutora, Professora do Programa de Pós Graduação em Ensino de Ciências e Matemática (PPGECIMAT) - Universidade Franciscana (UFN), anabulegon@ufn.edu.br
} 


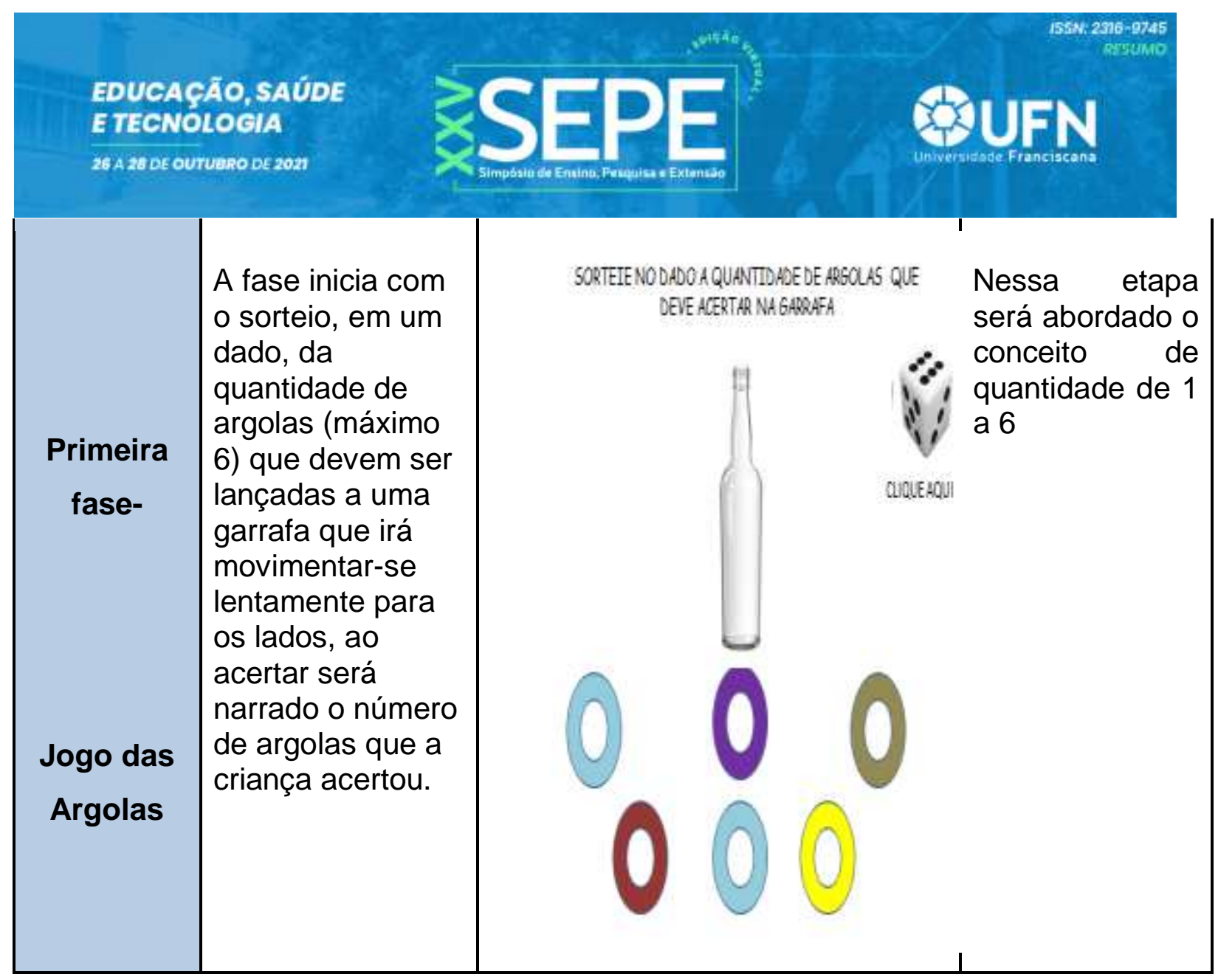

\footnotetext{
${ }^{1}$ Pedagoga, Mestranda do Programa de Pós-Graduação em Ensino de Ciências e Matemática (PPGECIMAT) - Mestrado Profissional - Universidade Franciscana (UFN), vivianeleal539@gmail.com 2 Doutora, Professora do Programa de Pós Graduação em Ensino de Ciências e Matemática (PPGECIMAT) - Universidade Franciscana (UFN), anabulegon@ufn.edu.br
} 


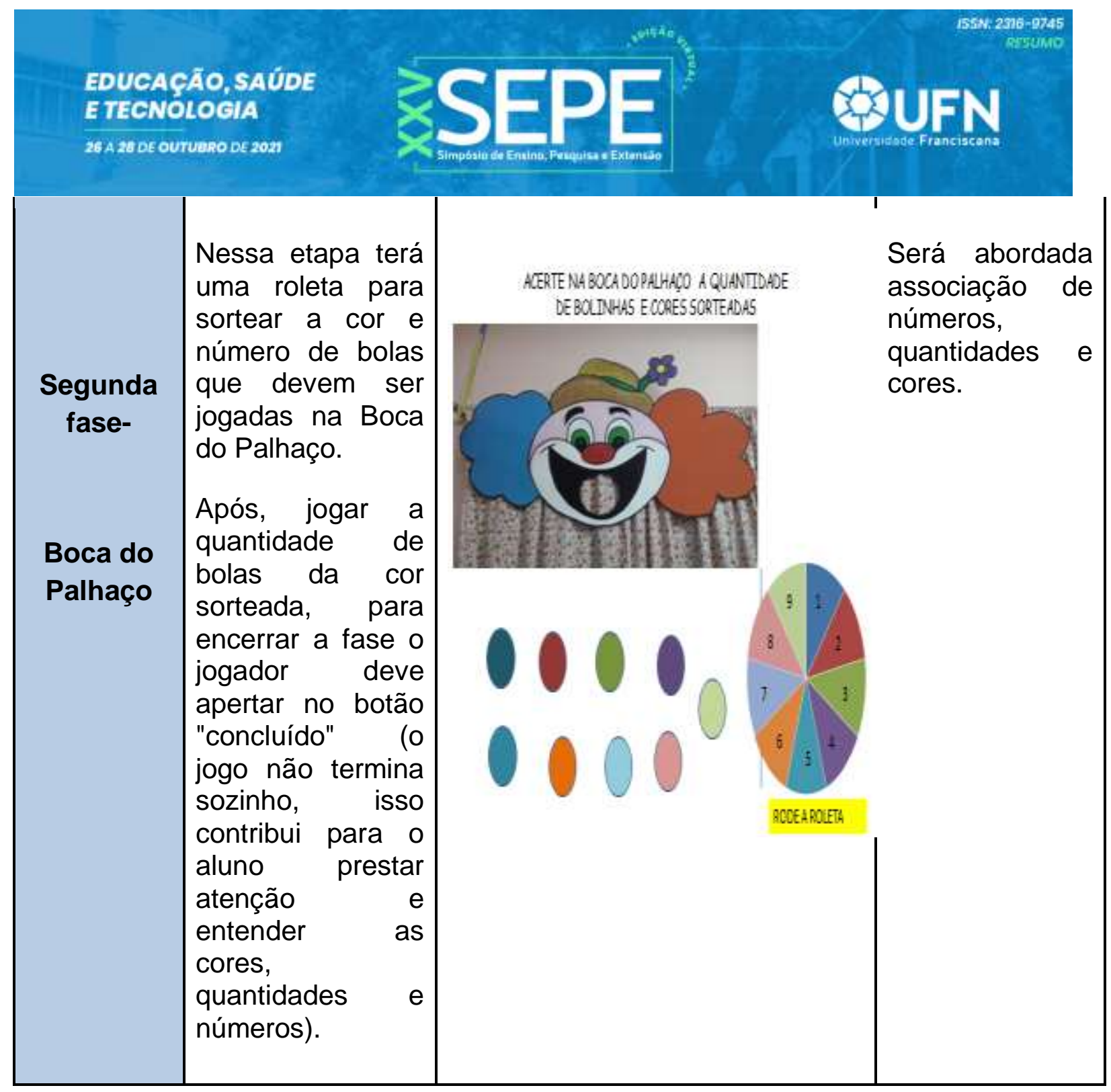

\footnotetext{
${ }^{1}$ Pedagoga, Mestranda do Programa de Pós-Graduação em Ensino de Ciências e Matemática (PPGECIMAT) - Mestrado Profissional - Universidade Franciscana (UFN), vivianeleal539@gmail.com 2 Doutora, Professora do Programa de Pós Graduação em Ensino de Ciências e Matemática (PPGECIMAT) - Universidade Franciscana (UFN), anabulegon@ufn.edu.br
} 


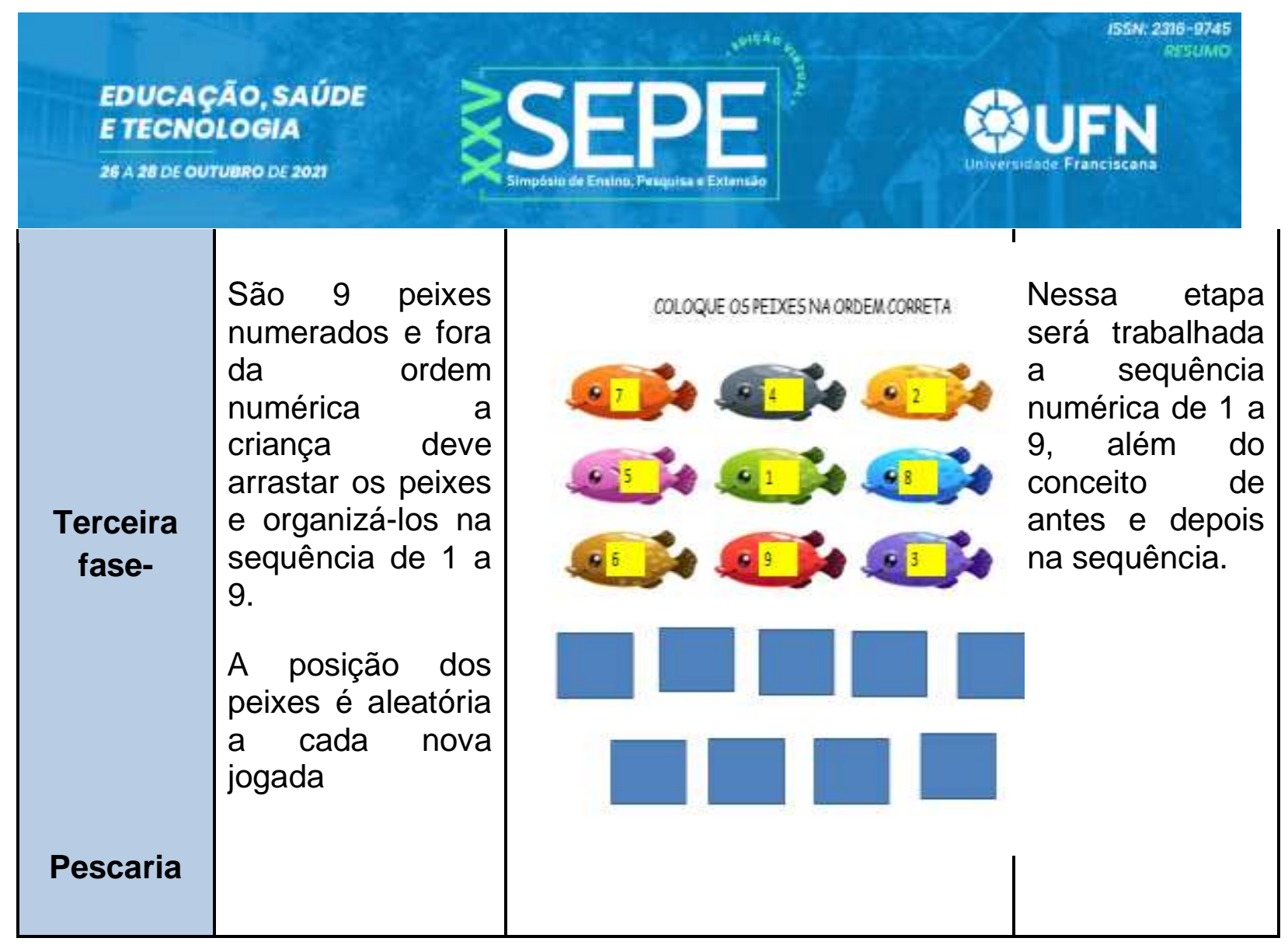

Fonte: as autoras

Todo o jogo será organizado com áudios explicativos incentivando a aprendizagem, facilitando a interação de crianças em processo de alfabetização.

A pontuação é expressa em forma de estrelas com o objetivo de motivar o interesse em aprender dos estudantes. Ao terminar a fase o jogador ganhará de 1 a 3 estrelas. As quantidades de estrelas conquistadas nas fases aparecem somadas no final do jogo.

Na primeira fase "Jogo das Argolas" a quantidade de estrelas ganhas varia de acordo com a quantidade de argolas/bolas a serem jogadas (quem precisa acertar mais argolas/bolas pode demorar bem mais tempo para completar a tarefa e ainda ganhar 3 estrelas, comparado a alguém que precisa acertar só 1 argola/bola, que tem poucos segundos para ganhar 3 estrelas.

$\mathrm{Na}$ segunda fase "Boca do palhaço" a etapa inicia com o sorteio em uma roleta do número e cor de bolinhas que devem ser acertadas no alvo (boca do palhaço). A criança só avança para a terceira fase clicando no botão concluído, então recebe de 1 a 3 estrelas na pontuação dependendo do tempo para acertar e concluir o desafio. Se o estudante não acertar a quantidade e cor e bolas que

\footnotetext{
${ }^{1}$ Pedagoga, Mestranda do Programa de Pós-Graduação em Ensino de Ciências e Matemática (PPGECIMAT) - Mestrado Profissional - Universidade Franciscana (UFN), vivianeleal539@gmail.com 2 Doutora, Professora do Programa de Pós Graduação em Ensino de Ciências e Matemática (PPGECIMAT) - Universidade Franciscana (UFN), anabulegon@ufn.edu.br
} 
EDUCAÇÃO, SAÚDE

ETECNOLOGIA

26A 28DE OUTUERO DE2021

sorteou e clicar no botão concluir receberá a mensagem "TENTE NOVAMENTE", assim repetirá o desafio proposto e irá clicar em concluído se tiver acertado prossegue para a última fase.

$\mathrm{Na}$ terceira fase "Pescaria" o jogador deve arrastar os peixes numerados e dispostos aleatoriamente para organizá-los na sequência numérica correta. Nessa etapa também são mostradas de 1 a 3 estrelas conquistadas pelo jogador, dependendo do tempo que levou para concluir a etapa.

Ao concluir as três fases aparecerá uma tela com a pontuação total, ou seja, o somatório de estrelas recebidas nas fases do jogo sendo de 3 ao máximo de 9 estrelas.

A pontuação com o sistema de estrelas de incentivo tem como intuito estimular o jogador a jogar mais vezes e continuar exercitando suas habilidades. Ao acertarem os desafio a cada fase, as estrelas serão conquistadas de 1 ao máximo 3, conforme tempo utilizado para desenvolver a sequência.

As crianças acessarão o jogo "Festa na Escola" nos computadores ou notebooks, disponíveis no Laboratório de Informática da escola, ou poderão levar e utilizar seus celulares para jogar. O professor deve combinar as regras com antecedência e clareza para que os estudantes compreendam a mecânica do jogo, tornando seu uso eficaz e com potencial de desenvolver aprendizagem significativa. As crianças também poderão utilizar esse jogo em espaços extraclasse, se quiserem.

\section{CONSIDERAÇÕES FINAIS}

Quando se pensa em produzir um jogo educacional digital, tenciona-se que ele seja utilizado por professores para auxiliar o processo de ensino e aprendizagem de determinados conceitos.

Os jogos educacionais digitais são recursos que podem ser utilizados em espaços escolares e extraclasse, favorecendo a aprendizagem ativa e ubíqua.

O jogo aqui apresentado é um material digital interativo, que pode ser jogado de forma individual ou em equipe, dentro ou fora da sala de aula. Os desafios

\footnotetext{
${ }^{1}$ Pedagoga, Mestranda do Programa de Pós-Graduação em Ensino de Ciências e Matemática (PPGECIMAT) - Mestrado Profissional - Universidade Franciscana (UFN), vivianeleal539@gmail.com 2 Doutora, Professora do Programa de Pós Graduação em Ensino de Ciências e Matemática (PPGECIMAT) - Universidade Franciscana (UFN), anabulegon@ufn.edu.br
} 
matemáticos propostos contemplam os conceitos de números e quantidades e são adequados às crianças do nível pré-escolar.

O caráter lúdico e de entretenimento, proposto no jogo, com brincadeiras, pontuações e estrelas, promovem o engajamento e estimulam as crianças a jogarem até o final. Além disso, desperta o interesse dos estudantes pelo estudo dos conceitos de Matemática para além dos espaços de sala de aula, ampliando, desse modo, o tempo destinado aos estudos escolares.

\section{REFERÊNCIAS}

BROUGÈRE, G. Jogo e educação. Porto Alegre: Artes Médicas, 1998.

GROS, B. The impact of digital games in education. First Monday, v. 8, n. 7, jul. 2003.

HUIZINGA, J. O jogo como elemento de cultura. São Paulo, Editora Perspectiva, 2001.

MOURA, Manoel O. de. Jogo, brincadeira e a educação. 11 Ed. São Paulo: Cortez, 2008.

POMMER, W. M. A Teoria das Situações Didáticas e a Dialética Ferramenta Objeto: um quadro comparativo. In: V SEMINÁRIO DE EDUCAÇÃO MATEMÁTICA DE NOVA ANDRADINA, 2013, Nova Andradina, Anais. Disponível em: https://revistas.pucsp.br/index.php/emp/article/view/45518 . Acesso em: 04 de mar de 2021.

SALLES, F.; FARIA V.. Currículo na educação infantil. 2. ed. São Paulo: Ática, 2012.

SAVI, Rafael; ULBRICHT, Vania R. Jogos digitais educacionais: benefícios e desafios. UFRGS. Porto Alegre. 2008. Disponível em: Acesso em 15 de jun. de 2021.

\footnotetext{
${ }^{1}$ Pedagoga, Mestranda do Programa de Pós-Graduação em Ensino de Ciências e Matemática (PPGECIMAT) - Mestrado Profissional - Universidade Franciscana (UFN), vivianeleal539@gmail.com 2 Doutora, Professora do Programa de Pós Graduação em Ensino de Ciências e Matemática (PPGECIMAT) - Universidade Franciscana (UFN), anabulegon@ufn.edu.br
} 